\title{
Dental status, dental treatment procedures and radiotherapy as risk factors for infected osteoradionecrosis (IORN) in patients with oral cancer - a comparison of two 10 years' observation periods
}

Marcus Niewald ${ }^{1 *}$, Kristina Mang ${ }^{2}$, Oliver Barbie ${ }^{3}$, Jochen Fleckenstein ${ }^{1}$, Henrik Holtmann ${ }^{4,5}$, Wolfgang J Spitzer ${ }^{4}$ and Christian Rübe ${ }^{1}$

\begin{abstract}
Objectives: Dental status, dental treatment procedures and radiotherapy dosage as potential risk factors for an infected osteoradionecrosis (IORN) in patients with oral cancers: Retrospective evaluation of 204 patients treated in two observation periods of approximately ten years each.

Patients and methods: In group A, 90 patients were treated in the years 1993-2003, in group B 114 patients in the years 1983-1992 (data in brackets). All patients had histopathologically proven squamous cell cancers, mainly UICC stages III and IV. $70 \%(85 \%$, n.s.) had undergone surgery before radiotherapy. All patients were referred to the oral and maxillofacial surgeon for dental rehabilitation before further treatment.

Radiotherapy was performed using a 3D-conformal technique with 4-6MV photons of a linear accelerator (Co-60 device up to 1987). The majority of patients were treated using conventional fractionation with total doses of 60-70 Gy in daily fractions of 2 Gy. Additionally, in group A, hyperfractionation was used applying a total dose of 72 Gy in fractions of $1.2 \mathrm{~Gy}$ twice daily (time interval $>6$ hours). In group B, a similar schedule was used up to a total dose of 82.8 Gy (time interval 4-6 hours). 14 (0) patients had radiochemotherapy simultaneously. After therapy, the patients were seen regularly by the radiooncologist and - if necessary - by the oral and maxillofacial surgeon. The duration of follow-up was 3.64 years ( 5 years, $p=0.004$ ).

Results: Before radiotherapy, the dental health status was very poor. On average, $21.5(21.2$, n.s.) teeth were missing. Further 2.04 teeth $(2.33$, n.s.) were carious, $1.4(0.3, p=0.002)$ destroyed.

Extractions were necessary in 3.6 teeth $(5.8, p=0.008)$, conserving treatment in $0.4(0.1, p=0.008)$ teeth. After dental treatment, $6.30(4.8$, n.s. $)$ teeth remained.

IORN was diagnosed after conventionally fractionated radiotherapy in $15 \%(11 \%$, n.s.), after hyperfractionation in $0 \%$ $(34 \%, p=0.01)$.

(Continued on next page)
\end{abstract}

\footnotetext{
* Correspondence: marcus.niewald@uks.eu

'Department of Radiotherapy and Radiooncology, Saarland University

Medical Center, Building 6.5, Kirrberger Strasse 100, D-66424 Homburg/Saar,

Germany

Full list of author information is available at the end of the article
} 
(Continued from previous page)

Conclusion: Within more than 20 years there was no improvement in dental status of oral cancer patients. Extensive dental treatment procedures remained necessary. There was an impressive reduction of the IORN frequency in patients treated in a hyperfractionated manner probably resulting from a dose reduction and an extension of the interfraction time.

Keywords: Oral cancer; Radiotherapy; Infected osteoradionecrosis; Dental status

\section{Background}

Infected osteoradionecrosis (IORN) is still one of the major problems after radiotherapy for neoplasms in the oral cavity. The chewing and swallowing functions of the patients are impaired, long-lasting conservative and surgical interventions may become necessary. In the last decades, there was an ample discussion about potential risk factors for the development of IORN. Besides the kind of surgical procedures, dosage and fractionation of radiotherapy and the simultaneous application of chemotherapy, the patients' dental status before treatment and the extent of dental treatment procedures were regarded significant.

Thus, more than 20 years ago, the departments of Radiotherapy and of Oral and Maxillofacial Surgery of the Saarland University Medical School together started a dental examination and rehabilitation program with the aim to prevent IORN as far as possible. All patients referred for radiotherapy for cancer in the oral cavity were examined by the oral and maxillofacial surgeon, the exact dental findings were recorded and - if necessary, specific rehabilitation procedures were performed. Radiotherapy was started only after approval by the Oral and maxillofacial surgeon (OMF surgeon). After therapy, the patients were seen regularly by the radiooncologist, diagnosis and treatment of IORN were performed by the oral and maxillofacial surgeon.

After completion of two theses (Barbie 1997; Mang 2011), published in (Niewald et al. 1996; Niewald et al. 2013) each analyzing a ten years' period of radiotherapy for oral cancer one after the other, we now had the unique possibility to reanalyze and to compare the data obtained in this very long observation period in terms of dental findings, dental rehabilitation procedures and the frequency of IORN.

\section{Methods}

Two groups of patients who had undergone radiotherapy for neoplasms of the oral cavity have been reanalyzed retrospectively:

Group A consists of 90 consecutive patients having been treated in the years 1993-2003.

Group B consists of 114 consecutive patients having been treated in the years 1983-1992 (data in brackets).
All patients suffered from squamous cell carcinoma of the oral cavity mainly in stages III and IV according to the Union Internationale contre le Cancer-(UICC)-definition, one patient had a local recurrence but had not been irradiated before. Patients with treated local or regional recurrences, distant metastases or with insufficient data were excluded. In group $B$, it seemed impossible to actualize the follow-up data, so that the data from the former analysis were taken. For this reason, no comparison of oncological results was attempted. In order to improve comparability, the inclusion criteria mentioned above were applied to both groups retrospectively which lead to the exclusion of several patients and a complete re-analysis of the data.

$70 \%$ of the patients in group A $(85 \%$, n.s.) had undergone surgery for the primary tumor and the regional lymph node regions. After surgery or after biopsy all patients were referred to the oral and maxillofacial surgeon for assessment of the dental status including an meticulous clinical and $\mathrm{x}$-ray examination. The dental treatment procedures were performed as early as possible with a minimal time interval of 7-10 days from the last procedure to the beginning of radiotherapy. All dental extractions were performed according to a written protocol under "special care" (primary tissue closure, perioperative antibiotics for 7-10 days beginning one day before surgery). In the nineties all patients were advised not to wear their dental prostheses up to 6-12 months after radiotherapy (today until complete healing of mucositis) (Curi and Dib 1997; Reuther et al. 2003). Radiotherapy was started after complete healing of the gingival wounds and thus approval by the OMF surgeon.

After production of a face mask for fixation, the computerized tomography for radiotherapy planning was performed, and the two- dimensional (up to 2000) or three-dimensional dose distribution was computed after target volume delineation. Radiotherapy was applied using 4-6MV photons (electrons for level V lymph node region) of a linear accelerator; a 60-Cobalt machine was in use additionally until 1987 . In the majority of patients $(\mathrm{n}=73$ in group $\mathrm{A}, \mathrm{n}=74$ in group $\mathrm{B})$, conventionally fractionated radiotherapy was applied with total doses of 60-70 Gy (details see Table 1) in daily single fractions of 2 Gy. Furthermore, different hyperfractionated schedules 
Table 1 Biographical and oncological data

\begin{tabular}{|c|c|c|c|c|}
\hline Item & & Group A & Group B & Remarks \\
\hline Mean age (years) & & 57.1 & 54.6 & n.s. \\
\hline Mean Karnofsky performance Index & & 7.8 & 7.5 & n.s. \\
\hline Follow-up (years) & & 4.1 & 5.0 & $p=0.004$ \\
\hline \multirow[t]{4}{*}{ T-stage } & $\mathrm{T} 1$ & $14(16 \%)$ & $20(18 \%)$ & n.s. \\
\hline & $\mathrm{T} 2$ & $33(37 \%)$ & $49(43 \%)$ & \\
\hline & T3 & $8(9 \%)$ & $19(16 \%)$ & \\
\hline & $\mathrm{T} 4$ & $35(38 \%)$ & $26(23 \%)$ & \\
\hline \multirow[t]{4}{*}{$\mathrm{N}$-stage } & No & $20(22 \%)$ & $46(40 \%)$ & n.s. \\
\hline & N1 & $23(26 \%)$ & $24(21 \%)$ & \\
\hline & N2 & $47(52 \%)$ & $30(26 \%)$ & \\
\hline & N3 & 0 & $14(13 \%)$ & \\
\hline \multirow[t]{4}{*}{ UICC stage } & I & $6(7 \%)$ & $10(9 \%)$ & n.s. \\
\hline & $\|$ & $7(8 \%)$ & $22(19 \%)$ & \\
\hline & III & $19(21 \%)$ & $26(23 \%)$ & \\
\hline & IV & $58(64 \%)$ & $56(49 \%)$ & \\
\hline \multirow[t]{2}{*}{ Pre-treatment } & None & $24(27 \%)$ & $17(15 \%)$ & $p<0.001$ \\
\hline & Surgery & $66(73 \%)$ & $97(85 \%)$ & \\
\hline \multirow[t]{13}{*}{ Total dose (Gy) } & Conventional fractionation & $N=75$ & $N=73$ & $p<0.001$ \\
\hline & & 30Gy (1) & $2 \mathrm{~Gy}(1)$ & \\
\hline & & 36Gy (1) & 8Gy (1) & \\
\hline & & 50Gy (7) & 36Gy (1) & \\
\hline & & 58Gy (2) & 44Gy (1) & \\
\hline & & 60Gy (32) & 56Gy (1) & \\
\hline & & 64Gy (9) & 60Gy (31) & \\
\hline & & 70Gy (23) & 62Gy (1) & \\
\hline & & & 66Gy (1) & \\
\hline & & & 70Gy (31) & \\
\hline & & & 72Gy (2) & \\
\hline & & & 76Gy (1) & \\
\hline & & & 80Gy (1) & \\
\hline \multirow[t]{7}{*}{ Total dose (Gy) } & Hyperfractionation & $N=15$ & $N=41$ & \\
\hline & & $55.8 \mathrm{~Gy}(1)$ & 13.2Gy (1) & \\
\hline & & 70.8Gy (1) & 81.6Gy (2) & \\
\hline & & 72.0Gy (11) & 82.8Gy (35) & \\
\hline & & 72.8Gy (1) & 85.2Gy (1) & \\
\hline & & 76.8Gy (1) & 85.5Gy (1) & \\
\hline & & & 87.8Gy (1) & \\
\hline \multirow[t]{4}{*}{ Daily fraction } & Conventional fractionation & $2.0 \mathrm{~Gy}(74)$ & $2.0 \mathrm{~Gy}(73)$ & $p=0.0012$ \\
\hline & & 3.0 Gy (1) & & \\
\hline & Hyperfractionation & 1.2 Gy (14) & $1.2 \mathrm{~Gy}(41)$ & \\
\hline & & 1.4 Gy (1) & & \\
\hline Simultaneous chemotherapy & & 14 & 0 & $p<0.001$ \\
\hline
\end{tabular}


were performed in both groups: in group A $(n=46)$ a total dose of 72 Gy was applied in single doses of 1.2 Gy twice daily (interfraction interval $>=6$ hours) to patients with formerly untreated tumors, in group B $(n=41)$ a total dose of 82.8 Gy in single doses of 1.2 Gy twice daily (interfraction interval 4-6 hours) was applied to patients with untreated and with resected tumors. Two patients in group A have been treated in a different manner (one with 1.4 Gy twice daily, another with a single dose of 3.0 Gy once daily).

14(0) patients received chemotherapy consisting of cisplatinum and 5-FU simultaneously due to their unfavourable tumour and nodal stage. No patients with chemotherapy were excluded from the evalution. During therapy, the patients received dental care by the local dental colleagues. Fluoridation was used according to dental advice. Splints were not normally used because of unfavourable experience of patients with aggravating radiation mucositis by applying fluoride jelly to the gingiva using these splints.

After radiotherapy, the patients were examined for locoregional result and possible side effects in the Department of Radiotherapy and Radiooncology. Dental follow-up was performed by their local dentists. Consequently, detailed data about this phase are not available. Patients with a suspicion of IORN were referred to the Dept. of Oral and Maxillofacial Surgery for further diagnosis and treatment.
The mean duration of follow-up was 3.64 years (5 years, $\mathrm{p}=0.004)$.

Infected osteoradionecrosis was minimally diagnosed when necrosis of the gingiva on top of the eroded bone became visible as infected mucosal ulcers with eroded mandibular bone underneath according to grade 2 or higher of the classification published by Schwartz et al. (Schwartz and Kagan 2002). Patients with manifest IORN were treated by the oral and maxillofacial surgeon in cooperation with the local dentist.

The patients' data were collected from the records in the Departments of Radiotherapy and Radiooncology and Oral and Maxillofacial Surgery. All (panoramic x-ray) examinations available have been reviewed, thus we are quite sure that a potential local recurrence has not been misdiagnosed as an IORN. Furthermore, standardized questionnaires were mailed to the patients' general medical practitioners and general dentists as well as the local authorities five times within the observation period in order to get additional data about freedom of local or regional recurrence, survival or the onset of IORN.

All data were entered into a medical databank (Medlog ${ }^{\mathrm{TM}}$, Parox, Muenster, Germany). Frequency distributions, means and standard deviations were computed. The groups were compared using the t-test (means) and the Kruskal-Wallace test (distributions). Overall survival and occurrence of IORN over time were computed using the Kaplan-Meier estimate, the comparison of the

Table 2 Dental findings before radiotherapy

\begin{tabular}{|c|c|c|c|c|}
\hline Teeth (mean values, $n=$ ) & Group A & Group B & Comparison: & Data available from $\mathrm{n}$ patients \\
\hline Absent & 22.0 & 21.2 & n.s. & 204 \\
\hline Present & 10.1 & 10.8 & n.s. & 204 \\
\hline Carious & 2.0 & 2.3 & n.s. & 198 \\
\hline Deeply carious destroyed & 1.4 & 0.3 & $p=0.002$ & 200 \\
\hline Loose & 1.6 & 2.2 & n.s. & 197 \\
\hline Root remainders & 0.3 & 0.4 & n.s. & 202 \\
\hline Devital & 0.5 & 1.0 & $p=0.023$ & 200 \\
\hline Roots - filled completely & 0.2 & 0.1 & n.s. & 198 \\
\hline Roots - filled incompletely & 0.3 & 0.1 & $p=0.006$ & 199 \\
\hline Apical periodontitis & 0.3 & 0.2 & n.s. & 200 \\
\hline Dentogenic cysts & 0.2 & 0.1 & n.s. & 199 \\
\hline Retained teeth & 0.2 & 0.1 & n.s. & 198 \\
\hline \multicolumn{5}{|c|}{ Superficial marginal periodontitis (patients) } \\
\hline - Localized & $7(8 \%)$ & $33(29 \%)$ & $p=0.002$ & 199 \\
\hline - General & $10(11 \%)$ & $16(14 \%)$ & & \\
\hline \multicolumn{5}{|c|}{ Profound marginal periodontitis (patients) } \\
\hline - Localized & $12(14 \%)$ & $25(22 \%))$ & $p=0.002$ & 201 \\
\hline - General & $35(40 \%)$ & $14(12 \%)$ & & \\
\hline
\end{tabular}

Superficial marginal periodontitis: chronic periodontitis with less to moderate attatchment loss. Profound marginal periodontitis: chronic periodontitis with severe attatchment loss. 
Table 3 Dental rehabilitation procedures

\begin{tabular}{lllll}
\hline Teeth (mean values, $\mathbf{n}=$ ) & Group A & Group B & Comparison & Data available from $\mathbf{n}$ patients \\
\hline Endodontic treatment & 0.05 & 0.03 & n.s. & 200 \\
Removal of root remainders & 0.2 & 0.4 & n.s. & 200 \\
Tooth extraction & 3.7 & 5.8 & $p=0.008$ & 202 \\
Conserving treatment & 0.6 & 0.1 & $p=0.008$ & 200 \\
Cystectomy & 0.09 & 0.05 & n.s. & 199 \\
Surgical removal & 0.3 & 0.2 & n.s. & 201 \\
Healthy teeth remaining after dental rehabilitation & 6.2 & 4.8 & n.s. & 201 \\
\hline
\end{tabular}

groups was performed using the Mantel-Haenszel test. Prognostic parameters for IORN were analyzed univariately by comparison of means and distributions in a group containing the patients with IORN compared to another group with the patients who never experienced IORN using the t-test, $\mathrm{u}$-test and chi-square test in the appropriate variables. Multivariate search for independent prognostic factors was performed by logistic regression.

Detailed biographical and oncological data have been summarized in Table 1.

All patients had given their written informed consent before dental examination and treatment as well as radiotherapy. The approval by the local ethics committee was dispensable due to the retrospective nature of this evaluation. This research is in compliance with the Declaration of Helsinki in its actual version.

\section{Results}

\section{General remarks}

In group A, up to July 2013, 58 patients were dead with a mean follow-up of $2.4[0-8.8]$ years. The patients known to be alive were seen irregularly, the most recent information resulted from questionnaires, nearly all patients were lost to follow-up after on average 7.4 [0-15] years.

In group $B, 77 / 114$ patients were dead with a mean follow-up of 3.4 [0-11.7] years. The patients known alive were lost to follow-up after on average 8.5 [4.3-13.3] years.

\section{Dental findings before radiotherapy}

The patients' dental status was generally poor. On average 10.1 (10.8) teeth were found present at the time of initial dental examination. For most of the criteria there was no statistically significant difference between the groups. However, we found significantly more destroyed teeth $(1.4$ vs. 0.3 teeth, $\mathrm{p}=0.002)$ in the more recent patient collective, Furthermore there were more roots filled incompletely ( 0.3 vs. 0.1 teeth, $\mathrm{p}=0.006)$. However, avital teeth were found less frequently in group A (0.5 vs. 1.0 teeth, $\mathrm{p}=0.023)$. Chronic periodontitis with less to moderate attachment loss was found less frequently $(\mathrm{p}=0.01)$ whereas chronic periodontitis with severe attachment

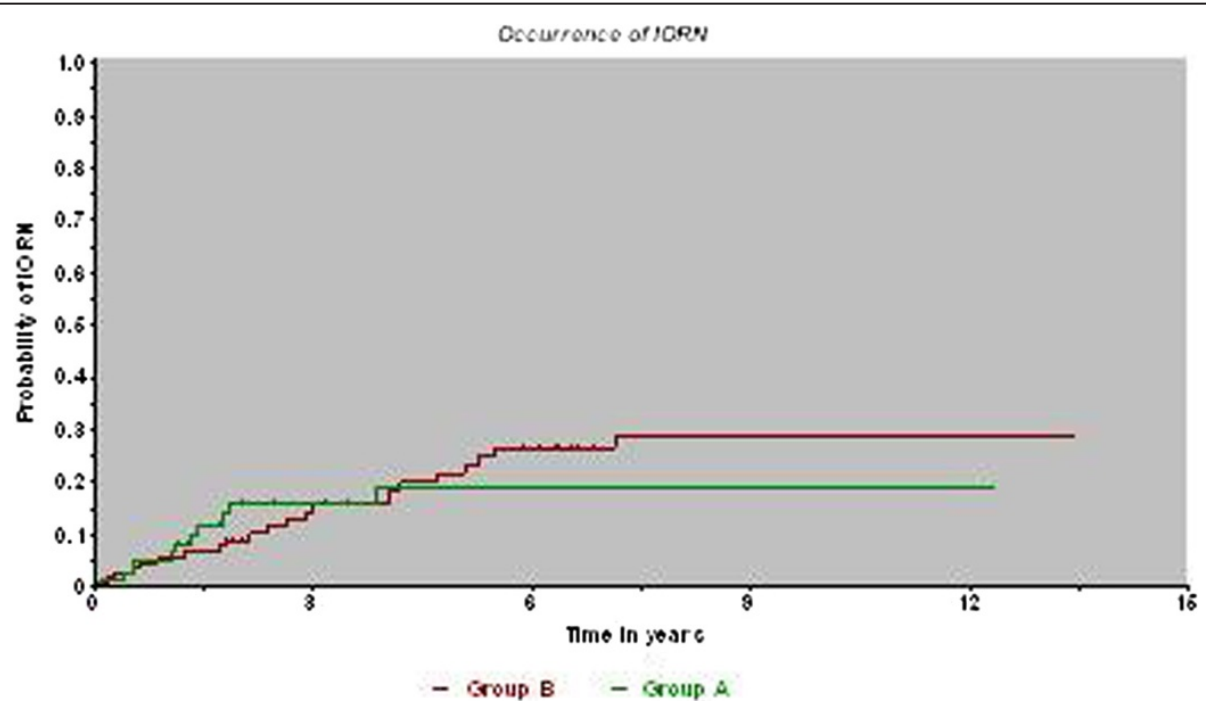

Figure 1 Development of IORN over time (Kaplan-Meier estimate). 
Table 4 Prognostic factors for the occurrence of IORN ( $\mathrm{n}=204)$

\begin{tabular}{ll}
\hline Univariate analysis & \\
\hline Teeth & $\mathbf{p}=$ \\
\hline Dental status before starting radiotherapy & \\
Absent & 0.110 \\
Present & 0.107 \\
Carious & 0.026 \\
Deeply carious destroyed & 0.202 \\
Loose & 0.104 \\
Root remainders & 0.595 \\
Devital & 0.287 \\
Roots - filled completely & 0.949 \\
Roots - filled incompletely & 0.789 \\
Apical periodontitis & 0.888 \\
Cysts & 0.392 \\
Retained & 0.1620 \\
Conservative treatment possible & 0.430 \\
No conservative treatment possible & 0.179 \\
Filled & 0.751 \\
Not sufficiently filled teeth & 0.549 \\
Teeth with not sufficient crowns & 0.968 \\
Item & \\
Chronic periodontitis with less to moderate & 0.418 \\
attatchment loss & \\
Localized & \\
General & \\
Chronic peilodontis with severe attatchmt & \\
\hline
\end{tabular}

Chronic periodontitis with severe attatchment loss $\quad 0.210$

Localized

General

Dental treatment before radiotherapy

Endodontic treatment 0.379

Removal of root remainders $\quad 0.636$

Tooth extraction $\quad 0.291$

Conserving treatment $\quad 0.603$

Cystectomy 0.936

Healthy teeth remaining after dental rehabilitation $\quad 0.158$

Demographic and oncological data

Age

0.106

Karnofsky performance status $\quad 0.625$

T-stage

$\mathrm{N}$-stage

Total dose

BED2

Daily fraction

110

\section{7}

104

.595

949
Remarks

Significant

(n)

Significant

(a)

Table 4 Prognostic factors for the occurrence of IORN

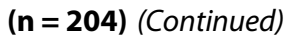

\begin{tabular}{|c|c|c|}
\hline \multicolumn{3}{|c|}{ Multivariate analysis } \\
\hline Carious teeth & 0.0089 & Significant \\
\hline N-stage & 0.1256 & \\
\hline Total dose & 0.3524 & \\
\hline BED 2 & 0.4182 & \\
\hline Daily fraction & 0.5596 & \\
\hline
\end{tabular}

loss was seen more frequently $(\mathrm{p}<0.001)$ in group A compared to group B. Detailed data have been depicted in Table 2.

We can summarize that dental status in these special patients has hardly changed over the decades. Data concerning dental biofilm or the use of dental prostheses had not been collected in group B, thus a comparison could not be performed.

\section{Dental rehabilitation procedures}

In the majority of criteria, the extent of dental rehabilitation procedures was identical in both groups. Tooth extractions were found more frequently in group B (3.7 vs. $5.8, \mathrm{p}=0.008$ ) whereas conserving treatment was performed more frequently in Group A (0.6 vs. 0.1, $\mathrm{p}=0.008)$. Detailed data are summarized in Table 3.

\section{Frequency and risk factors of infected osteoradionecrosis (IORN)}

IORN was found in the corpus region of the mandible in $11 / 90$ patients (12\%) of group A and 22/114 patients (19\%) of group B (n.s.). The one-year prevalence was 5\%, the two- and three-year prevalence 15\%. A subgroup analysis dividing the collectives into two groups each with the patients having been treated with conventional fractionation or with hyperfractionation yielded the following results:

After conventional fractionation IORN was found in group A in $11 / 74$ patients (15\%), in group B in $8 / 73$ patients (11\%, differences n.s.). After hyperfractionation, IORN was not diagnosed in group A wheras it was observed in $14 / 41$ patients $(34 \%)$ in group B $(\mathrm{p}=0.01)$.

The Kaplan-Meier estimate showed that IORN normally occurred in the first two years in group A (first five years in group B) after radiotherapy (differences n.s.), after that time the risk remained stable (Figure 1). The subgroup analysis mentioned above resulted in identical curves for patients irradiated conventionally and highly different (but not statistically significant) curves after hyperfractionation.

The search for prognostically significant factors for the occurrence of IORN was performed using the whole patient collective consisting of 204 patients. The number 
of carious teeth, the $\mathrm{N}$-stage, the total dose, the size of the daily fractions and the BED2 (Biologically effective dose 2 Gy) were found prognostically significant in univariate analysis. These factors were entered into the multivariate analysis where solely the number of carious teeth was found significant (details are depicted in Table 4). The multivariate analysis showed the number of carious teeth a nearly significant prognostic factor, furthermore, the fractionation was found to be trendwise significant. All further factors mentioned in Tables 1 and 2 tested univariately were found insignificant. Further details are depicted in Table 4.

We did not try to compare the oncological data like local and regional tumor outcome or survival because it seemed impossible to achieve reliable data for group B nearly 20 years after treatment. Thus, we could not correlate the frequency of IORN to a local recurrence.

\section{Discussion}

Dental health status and dental rehabilitation procedures From our data we can summarize that - despite all effort in dental prophylaxis - the dental status of patients with oral neoplasms did not improve" over decades nor did the extent of dental rehabilitation procedures necessary before the start of radiotherapy.

The comparison of our data to those of the Forth German Trial of Oral Health (Kern et al. 2006) resulted in marked differences: In this study adults (33-44 years of age) on average 14.5 teeth were found carious, in older people ( $>=45$ years of age) 22.1 teeth. These teeth were rehabilitated completely in $95.6 \%$ and in
$94.8 \%$, respectively. A mean of 2.77 teeth in adults and of 14.2 teeth in older people were missing. $72 \%$ of the adults and $60.6 \%$ of the seniors were found to perform sufficient mouth hygiene. All these values were improved compared to the results of a former trial in 1997. On the other hand, the frequency of periodontitis was rising (moderate in $52.9 \%$ and intense in $39.8 \%$ of the population). Compared to those data our findings in patients with oral neoplasms were much more unfavourable and did not improve over time.

Further equally detailed analyses were rare. Jham et al. (Jham et al. 2008) reported in 2008 a collective of 207 patients with head and neck cancer with similar dental findings to our investigation detecting periodontal disease in $41 \%$, retained roots in $21 \%$, carious teeth in $12 \%$, and unerupted teeth in $5.8 \%$ of their patients, resulting in an IORN rate of $5.5 \%$. Schuurhuis et al. summarized 2011 the data of 185 patients and found oral infectious foci in $75 \%$, a periodontal pocket depth of more than $6 \mathrm{~mm}$ in 23\%, severe caries in 4\%, impacted teeth in 4\%, and residual root tips in $3 \%$. Tooth extractions had to be performed in $30 \%$ of the patients, a mean of 7.7 teeth had to be removed. Periodontal treatment was performed in $6 \%$. IORN was diagnosed in 11\% (Schuurhuis et al. 2011). Further literature data on this topic have been summarized in Table 5. In general, tumor patients frequently showed a noncompliance in routine dental care and daily oral hygiene. Tumor diagnosis did not change the patients' habits: Lockhart and Clark stated in 1994 that $97 \%$ of their patients needed dental care before radiotherapy, but only $81 \%$ underwent the indicated treatment.

Table 5 Dental status and rehabilitation procedures in the literature for IORN in the lower jaw

\begin{tabular}{|c|c|c|c|}
\hline Author group & Dental status & Rehabilitation procedures & Remarks \\
\hline $\begin{array}{l}\text { Frydrych and Slack-Smith } 2011 \\
(\mathrm{n}=82)\end{array}$ & No information & No information & $\begin{array}{l}\text { Average (median) date of last dental visit: } \\
66.76 \text { months ( } 18 \text { months) before radiotherapy }\end{array}$ \\
\hline \multirow{4}{*}{$\begin{array}{l}\text { Guggenheimer and Hoffman } \\
1994(n=947)\end{array}$} & Edentulous: 59\% & \multirow[t]{4}{*}{ No information } & \\
\hline & Partially edentulous: 9\% & & \\
\hline & $\begin{array}{l}\text { Poor dentition with no } \\
\text { replacement: } 14 \%\end{array}$ & & \\
\hline & Intact dentition: 18\% & & \\
\hline \multirow[t]{3}{*}{ Maier et al. $1993(n=100)$} & \multirow{2}{*}{$\begin{array}{l}\text { Tumour vs. control patients: } \\
\text { Tartar > } 3 \text { mm: } 40.91 \text { vs. } 21.98 \%\end{array}$} & \multirow[t]{3}{*}{ No information } & Tumour vs. control patients \\
\hline & & & Never tooth brushing 44.9 vs. $23.5 \%$ \\
\hline & $\begin{array}{l}\text { Decayed teeth }>50 \%: 27.2 \text { vs. } \\
3.9 \%\end{array}$ & & Dental visit more than once a year: $6 \%$ vs. $43.5 \%$ \\
\hline \multirow{3}{*}{$\begin{array}{l}\text { Lockhart and Clark } 1994 \\
(n=131)\end{array}$} & Alveolar bone loss: $66 \%$ & Needing dental care: 97\% & Noncompliant with routine dental care: $76 \%$ \\
\hline & Clinical caries: $71 \%$ & \multirow{2}{*}{$\begin{array}{l}\text { Did not seek the indicated } \\
\text { treatment: } 81 \%\end{array}$} & \multirow[t]{2}{*}{ Noncompliant with routine oral hygiene: $65 \%$} \\
\hline & Failing restorations: 91\% & & \\
\hline \multirow[t]{4}{*}{ Jham et al. $2008(n=207)$} & Periodontal disease: 41\% & \multirow[t]{4}{*}{ No information } & \\
\hline & Residual root: $21.2 \%$ & & \\
\hline & Caries $12 \%$ & & \\
\hline & Unerupted tooth: $5.8 \%$ & & \\
\hline
\end{tabular}




\section{Frequency of IORN}

The frequency of IORN was almost equal in both groups. However, the influence of fractionation was interesting. The rates of IORN were identical after conventional fractionation over the decades. However, while in group $B$ an unacceptably high amount of IORN was diagnosed after hyperfractionation, we did not see any IORN in group A. One reason may be the reduction of the total dose from 82.8 Gy to $72 \mathrm{~Gy}$, another one the extension of the interfraction interval from 4-6 to generally $>6$ hours, this relevance of interfractional time intervals for cell recovery was not yet known during radiotherapy of group B patients (Fowler, J., personal communication, approx. 1988).

In the literature, the incidence of IORN varied widely $(0-74 \%)$ as depicted in Table 6 whereas the majority of data are in a range of $5-10 \%$. However, the comparison of these values to each other and to our results is very difficult because of a different definition of staging of IORN, different tumor localizations, therapy schedules, radiation techniques and dosages results fit well within the range of data taken from the literature (Kim et al. 1974; Niewald et al. 1996). One of the data sets in the literature most comparable to our dataset has been published by Lee et al. (Lee et al. 2008) who experienced comparable IORN frequencies in a collective of patients having been operated on mainly.

\section{Risk factors for the occurrence of IORN}

Numerous prognostic factors for the development of IORN have been tested and published. A selection of these is summarized in Table 7. The localization of the primary tumor in the oral cavity with its microbial colonization and the abundant involvement of the mandibular bone with its unique blood supply probably promotes IORN. Unfavorable dental status, periodontal disease and soreness of the gingiva by pressure triggered by dental prosthesis are important as well as dental extractions before and especially after radiotherapy.

Radiation dose should not exceed $60-66$ Gy to the mandibular bone whenever possible, the target volume extending to the bone should be limited. Some authors regard hyperfractionation as a risk factor for IORN. In our ancient publication on this topic (Niewald et al. 1996) we experienced a very high frequency of IORN after hyperfractionated radiotherapy which may have been caused by too high total doses on the one hand and a too short interfraction interval (time interval between the two daily fractions) on the other hand. Both factors have been taken into account since 1992, consequently the results were improved markedly.

Intensity modulated radiotherapy (IMRT) has been found advantageous compared to conventional 3D-planned
Table 6 Incidence of IORN of the upper and lower jaw in the literature

\begin{tabular}{|c|c|c|}
\hline Author group & Incidence & Remarks \\
\hline \multirow{4}{*}{$\begin{array}{l}\text { Ben-David et al. } 2007 \\
(n=176)\end{array}$} & \multirow[t]{4}{*}{0} & Multiple tumour localizations \\
\hline & & Primary treatment (no surgery) \\
\hline & & IMRT \\
\hline & & 108/176 radiochemotherapy \\
\hline $\begin{array}{l}\text { Berger and } \\
\text { Bensadoun } 2010\end{array}$ & $1-5 \%$ & Literature survey \\
\hline $\begin{array}{l}\text { Crombie et al. } 2012 \\
(n=54)\end{array}$ & $36 \%$ & 53/54 radiochemotherapy \\
\hline \multirow{2}{*}{$\begin{array}{l}\text { Gomez et al. } 2011 \\
(\mathrm{n}=168)\end{array}$} & \multirow[t]{2}{*}{$1.2 \%$} & Multiple tumour localizations \\
\hline & & IMRT \\
\hline $\begin{array}{l}\text { Gomez et al. } 2009 \\
(n=35)\end{array}$ & $5 \%$ & IMRT \\
\hline $\begin{array}{l}\text { Jereczek-Fossa and } \\
\text { Orecchia } 2002\end{array}$ & $0.4-56 \%$ & Literature survey \\
\hline $\begin{array}{l}\text { Jham et al. } 2008 \\
(n=207)\end{array}$ & $5.5 \%$ & \multirow[t]{2}{*}{ Head and neck cancer } \\
\hline $\begin{array}{l}\text { Katsura et al. } 2008 \\
(n=39)\end{array}$ & $15 \%$ & \\
\hline $\begin{array}{l}\text { Lee et al. } 2008 \\
(n=189)\end{array}$ & $6.6 \%$ & Oral cavity and oropharynx \\
\hline $\begin{array}{l}\text { Monnier et al. } 2011 \\
(n=73)\end{array}$ & $40 \%$ & \multirow[t]{2}{*}{ Oral cavity and oropharynx } \\
\hline $\begin{array}{l}\text { Oh et al. } 2004 \\
(n=81)\end{array}$ & $4.9 \%$ & \\
\hline $\begin{array}{l}\text { Reuther et al. } 2003 \\
(n=830)\end{array}$ & $8.2 \%$ & Oral cavity and oropharynx \\
\hline $\begin{array}{l}\text { Stenson et al. } 2010 \\
(n=27)\end{array}$ & $18.4 \%$ & $\begin{array}{l}\text { Surgery, adjuvant } \\
\text { radiochemotherapy }\end{array}$ \\
\hline $\begin{array}{l}\text { Storey et al. } 2001 \\
(n=83)\end{array}$ & $6 \%$ & $\begin{array}{l}\text { Malignant submandibular } \\
\text { tumours }\end{array}$ \\
\hline \multirow{3}{*}{$\begin{array}{l}\text { Studer et al. } 2011 \\
(n=304)\end{array}$} & \multirow{3}{*}{$\begin{array}{l}\text { Grade } 2 \\
\text { EORTC: } 1.6 \%\end{array}$} & Oral cavity and oropharynx \\
\hline & & $\begin{array}{l}\text { Conventional dental care vs. } \\
\text { risk-adapted dental care }\end{array}$ \\
\hline & & IMRT \\
\hline Thiel 1989 & $4-35 \%$ & Literature survey \\
\hline $\begin{array}{l}\text { Thorn et al. } 2000 \\
(n=80)\end{array}$ & $74 \% / 3$ years & Multiple tumour localizations \\
\hline $\begin{array}{l}\text { Tsai et al. } 2012 \\
(n=402)\end{array}$ & $7.5 \%$ & $\begin{array}{l}\text { Oropharyngeal cancer, median } \\
\text { time to IORN } 8 \text { months }\end{array}$ \\
\hline $\begin{array}{l}\text { Turner et al. } 1996 \\
(n=333)\end{array}$ & $5.9 \%$ & \\
\hline
\end{tabular}

radiotherapy. Additional factors may be chemotherapy, higher body mass index and the use of steroids.

An important paper has been published by Tsai et al. in 2013 (Tsai et al. 2012). They reviewed the records of patients with small oropharyngeal cancers having undergone radiotherapy or radiochemotherapy. The overall prevalence of IORN was 7.5\%, higher doses, use of nicotine and alcohol, dental status as well as more advanced 
Table 7 Risk factors for IORN of the upper and lower jaw in the literature

\begin{tabular}{|c|c|c|}
\hline Author group & Risk factor(s) & Remarks \\
\hline Ahmed et al. 2009 & $\begin{array}{l}\text { Intensity modulated radiotherapy (IMRT) advantageous } \\
\text { compared to conventional radiotherapy }\end{array}$ & \\
\hline Berger and Bensadoun 2010 & Total dose >66 Gy & Literature survey \\
\hline \multirow[t]{3}{*}{ Bhide et al. 2012} & Total dose > 60 Gy & \multirow[t]{3}{*}{ Literature survey } \\
\hline & $\begin{array}{l}\text { Volume of mandible within the treatment field. Trauma related ORN after } \\
\text { lower doses }\end{array}$ & \\
\hline & IMRT & \\
\hline \multirow[t]{7}{*}{ Chopra et al. 2011} & White ethnicity & \\
\hline & Secondary infection & \\
\hline & Advanced age & \\
\hline & Stage IV & \\
\hline & Total dose & \\
\hline & Post-RT dental extractions & \\
\hline & Lack of pre-RT dental extractions & \\
\hline \multirow[t]{8}{*}{ Curi and Dib 1997, 2007} & Oral cancer & \\
\hline & Invasion of bone & \\
\hline & Tumour surgery & \\
\hline & Total radiation dose & \\
\hline & Dose rate/day & \\
\hline & Mode of radiation delivery & \\
\hline & Dental status & \\
\hline & Time from radiation therapy until the onset of ORN & \\
\hline \multirow[t]{3}{*}{ Goldwasser et al. 2007} & Higher body mass index & \multirow[t]{3}{*}{ Multivariate analysis } \\
\hline & Use of steroids & \\
\hline & Radiation dose >66 Gy & \\
\hline \multirow{8}{*}{$\begin{array}{l}\text { Jereczek-Fossa and Orecchia } \\
2002\end{array}$} & Total dose & \multirow{8}{*}{$\begin{array}{l}\text { Literature survey, only part of the factions } \\
\text { mentioned in the paper cited here }\end{array}$} \\
\hline & Brachytherapy dose & \\
\hline & Dose per fraction & \\
\hline & Interval between fractions & \\
\hline & $\begin{array}{l}\text { Volume of the horizontal ramus of the mandible irradiated } \\
\text { with a high dose }\end{array}$ & \\
\hline & Dental status & \\
\hline & Bad oral hygiene & \\
\hline & Dental extractions after radiotherapy & \\
\hline \multirow[t]{5}{*}{ Katsura et al. 2008} & Oral health status after radiotherapy & \\
\hline & Periodontal pocket depth & \\
\hline & Dental plaque & \\
\hline & Alveolar bone loss level & \\
\hline & Radiographic periodontal status & \\
\hline \multirow[t]{3}{*}{ Lee et al. 2009} & Univariate: Mandibular surgery & Multivariate analysis: \\
\hline & Co-60 & Mandibular surgery \\
\hline & & BED >106.2 Gy \\
\hline \multirow[t]{2}{*}{ Lozza et al. 1997} & Dose rate & \multirow[t]{2}{*}{ Brachytherapy exclusively } \\
\hline & Reference volume & \\
\hline
\end{tabular}


Table 7 Risk factors for IORN of the upper and lower jaw in the literature (Continued)

\begin{tabular}{|c|c|c|}
\hline \multirow[t]{4}{*}{ Monnier et al. 2011} & Oral cavity tumours & Multivariate analysis: bone surgery \\
\hline & Bone invasion & \\
\hline & Surgery prior to radiotherapy & \\
\hline & Bone surgery & \\
\hline \multirow[t]{2}{*}{ Nabil 2012} & Hyperfractionation & Literature survey \\
\hline & Reduced risk after accelerated radiotherapy with reduced dose & \\
\hline \multirow[t]{4}{*}{ Reuther et al. 2003} & Advanced tumours & \\
\hline & Segmental resection of the mandible & \\
\hline & Tooth extractions (pre/post RT) & \\
\hline & Pre-surgical radiotherapy worse than post-surgical radiotherapy & \\
\hline \multirow[t]{2}{*}{ Store and Boysen 2000} & Tumour localization in tongue and floor of mouth & \\
\hline & Trauma & \\
\hline \multirow[t]{7}{*}{ Thiel 1989} & Caries & \\
\hline & Periondontosis & \\
\hline & Periapical pathology & \\
\hline & Injury & \\
\hline & Irritation by prostheses & \\
\hline & Dental extractions before and after radiotherapy & \\
\hline & Bone surgery because of remaining or recurrent tumours & \\
\hline \multirow[t]{4}{*}{ Thorn et al. 2000} & Removal of teeth & \\
\hline & Surgery & \\
\hline & Injury from prosthesis & \\
\hline & Spontaneous breakdowns & \\
\hline \multirow[t]{5}{*}{ Tsai et al. 2012} & Total dose & \\
\hline & Dental status & \\
\hline & Smokers & \\
\hline & Alcohol & \\
\hline & Larger tumours & \\
\hline \multirow[t]{6}{*}{ Turner et al. 1996} & Bone involvement & \\
\hline & Synchronous Methotrexate & \\
\hline & Scattered dose from elective neck treatment & \\
\hline & Increasing dose & \\
\hline & Increasing target volumes for doses <55 Gy & \\
\hline & Dental extractions & \\
\hline
\end{tabular}

tumors were found significant risk factors for the development of IORN. In contrast to this paper our patients' primary situation seems more unfavorable: we only examined patients with oral cancer where the whole mandible was within the 100\%-isodose, thus we applied even higher doses to a large amount of bone. Furthermore, older techniques have been used; unfortunately, no information about fractionation has been given. Consequently, a higher prevalence of IORN here seems to be explainable.

Unfortunately, we did not succeed in identifying clearly significant independent prognostic factors for the development of IORN. In our patient collective, hyperfractionation seemed to have a protective effect whereas this could not be examined further due to the small number of events. In our dataset the number of carious teeth was found to be the only independent prognostic factor after multivariate analysis. Univariately, total dose and BED2 were significant which could be expected. In majority of patients, the total doses lie in a narrow range of 60-82 Gy which may have been a reason for the result, additionally the fact that few IORN cases have been observed.

The authors are well aware of the limitations of this retrospective evaluation. In this nearly homogenous collective of patients with oral cavity cancer having 
undergone radiotherapy +/- surgery, we have found complete data sets with respect to the dental status and restoration procedures of nearly all patients. The IORN data have been investigated meticulously, but due to the known incompliance of head and neck patients we could not exclude that single events did not become known to the authors.

\section{Conclusions}

The patients' dental status before radiotherapy was very poor compared to an otherwise healthy population. Apparently we did not succeed in improving these findings over the decades despite all effort in terms of dental prophylaxis. Consequently, extensive dental rehabilitation procedures had to be performed which did not change over time as well.

Examining patients irradiated with conventional fractionation, the incidence of IORN was found constant in a range of $10-15 \%$ over time. As stated earlier, the influence of the interfraction interval and of very high doses became known after the patients in group B had been irradiated, we thus diagnosed an unacceptably high frequency of IORN which became virtually zero after reduction of the total dose and extension of the interfraction interval. The multivariate search for prognostic factors only resulted in the assumption that dental status and fractionation could influence the occurrence of IORN.

\section{Abbreviations \\ BED2: Biologically effective dose ( $\alpha / \beta=2$ Gy); DEGRO: German society for radiation oncology; IMRT: Intensity modulated radiotherapy; IORN: Infected osteoradionecrosis; ORN: Osteoradionecrosis; UICC: Union internationale contre le cancer.}

\section{Competing interests}

The authors declare that they have no competing interests.

\section{Authors' contributions}

M.N. supervised the theses written by K.M and O.B. and wrote the manuscript. K.M. collected and evaluated the data in collective A. O.B. collected and evaluated the data in collective B. J.F. was mostly responsible for planning and delivering of radiotherapy, furthermore he corrected and approved the manuscript. H.H. corrected and approved the manuscript from the viewpoint of an oral and maxillofacial surgeon. W.J.S. supervised dental diagnosis and treatment and revised the manuscript. C.R. supervised radiotherapy and revised the manuscript. All authors read and approved the final manuscript.

\section{Acknowledgements}

The authors wish to acknowledge Dr. rer. nat. Norbert Licht, Head Physicist and his colleagues for computing the radiotherapy plans and many fruitful discussions.

Furthermore we wish to thank the doctors, nurses and secretaries in the two departments involved here who performed the patients' treatment and furthermore were of important help in searching for the files and contacting the patients. Furthermore, PD Dr. Stefan Gräber, Dept. of Medical Biometry, Epidemiology and Medical Informatics of the Saarland University Medical School is acknowledged for statistical advice.

A small part of these data has been published as a poster at the DEGRO 2013 congress (German Society of Radiation Oncology).

\section{Author details}

${ }^{1}$ Department of Radiotherapy and Radiooncology, Saarland University Medical Center, Building 6.5, Kirrberger Strasse 100, D-66424 Homburg/Saar, Germany. ${ }^{2}$ Dental Practice, Duisburg, Germany. ${ }^{3}$ Dental Practice, Lebach, Germany. ${ }^{4}$ Department of Oral and Maxillofacial Surgery, Saarland University Medical Center, Homburg/Saar, Germany. ${ }^{5}$ Present address: Department of Cranio-and-Maxillo Facial Surgery, Düsseldorf University Medical School, Düsseldorf, Germany.

\section{Received: 21 February 2014 Accepted: 16 May 2014}

Published: 23 May 2014

\section{References}

Ahmed M, Hansen VN, Harrington KJ, Nutting CM (2009) Reducing the risk of xerostomia and mandibular osteoradionecrosis: the potential benefits of intensity modulated radiotherapy in advanced oral cavity carcinoma. Med Dosim 34(3):217-224, doi:10.1016/j.meddos.2008.08.008

Barbie O (1997) Risikofaktoren und Dosis-Effekt-Beziehungen der Osteoradionekrose nach hyperfraktionierter und konventionell fraktionierter Strahlentherapie von Mundhöhlenkarzinomen - eine retrospektive Studie. Thesis, Saarland University, Homburg/Saar, Germany

Ben-David MA, Diamante M, Radawski JD, Vineberg KA, Stroup C, Murdoch-Kinch CA, Zwetchkenbaum SR, Eisbruch A (2007) Lack of osteoradionecrosis of the mandible after intensity-modulated radiotherapy for head and neck cancer: likely contributions of both dental care and improved dose distributions. Int J Radiat Oncol Biol Phys 68(2):396-402, doi:10.1016/j.ijrobp.2006.11.059

Berger A, Bensadoun RJ (2010) [Normal tissue tolerance to external beam radiation therapy: the mandible]. Cancer Radiother 14(4-5):295-300, doi:10.1016/j.canrad.2010.03.011

Bhide SA, Ahmed M, Newbold K, Harrington KJ, Nutting CM (2012) The role of intensity modulated radiotherapy in advanced oral cavity carcinoma. J Cancer Res Ther 8 Suppl 1:S67-S71, doi:10.4103/0973-1482.92218

Chopra S, Kamdar D, Ugur OE, Chen G, Peshek B, Marunick M, Kim H, Lin HS, Jacobs J (2011) Factors predictive of severity of osteoradionecrosis of the mandible. Head Neck 33(11):1600-1605, doi:10.1002/hed.21654

Crombie AK, Farah C, Tripcony L, Dickie G, Batstone MD (2012) Primary chemoradiotherapy for oral cavity squamous cell carcinoma. Oral Oncol. doi:10.1016/j.oraloncology.2012.03.027

Curi MM, Dib LL (1997) Osteoradionecrosis of the jaws: a retrospective study of the background factors and treatment in 104 cases. J Oral Maxillofac Surg 55(6):540-544, discussion 545-546

Curi MM, Oliveira dos Santos M, Feher O, Faria JC, Rodrigues ML, Kowalski LP (2007) Management of extensive osteoradionecrosis of the mandible with radical resection and immediate microvascular reconstruction. J Oral Maxillofac Surg 65(3):434-438, doi:10.1016/j.joms.2005.12.068

Frydrych AM, Slack-Smith LM (2011) Dental attendance of oral and oropharyngeal cancer patients in a public hospital in Western Australia. Aust Dent J 56(3):278-283

Goldwasser BA, Chuang S-K, Kabal LB, August M (2007) Risk factor assessment for the development of osteoradionecrosis. J Oral Maxillofac Surg 65:2311-2316

Gomez DR, Zhung JE, Gomez J, Chan K, Wu AJ, Wolden SL, Pfister DG, Shaha A, Shah JP, Kraus DH, Wong RJ, Lee NY (2009) Intensity-modulated radiotherapy in postoperative treatment of oral cavity cancers. Int J Radiat Oncol Biol Phys 73(4):1096-1103, doi:10.1016/j.jirobp.2008.05.024

Gomez DR, Estilo CL, Wolden SL, Zelefsky MJ, Kraus DH, Wong RJ, Shaha AR, Shah JP, Mechalakos JG, Lee NY (2011) Correlation of osteoradionecrosis and dental events with dosimetric parameters in intensity-modulated radiation therapy for head-and-neck cancer. Int J Radiat Oncol Biol Phys 81(4):e207-e213, doi:10.1016/j.jijrobp.2011.02.003

Guggenheimer J, Hoffman RD (1994) The importance of screening edentulous patients for oral cancer. J Prosthet Dent 72(2):141-143

Jereczek-Fossa BA, Orecchia R (2002) Radiotherapy-induced mandibular bone complications. Cancer Treat Rev 28(1):65-74, doi:10.1053/ctrv.2002.0254

Jham BC, Reis PM, Miranda EL, Lopes RC, Carvalho AL, Scheper MA, Freire AR (2008) Oral health status of 207 head and neck cancer patients before, during and after radiotherapy. Clin Oral Investig 12(1):19-24, doi:10.1007/ s00784-007-0149-5

Katsura K, Sasai K, Sato K, Saito M, Hoshina H, Hayashi T (2008) Relationship between oral health status and development of osteoradionecrosis of the mandible: a retrospective longitudinal study. Oral Surg Oral Med Oral Pathol Oral Radiol Endod 105(6):731-738 
Kern R, Krämer J, Michaelis W (2006) Vierte Deutsch Mundgesundheitsstudie des Instituts der Deutschen Zahnärzte. Bundeszahnärztekammer, Berlin

Kim JH, Chu FC, Pope RA, Woodard HQ, Bragg DB, Shidnia H (1974) Proceedings: time dose factors in radiation induced osteitis. Am J Roentgenol Radium Ther Nucl Med 120(3):684-690

Lee JA, Huh SJ, Oh D, Bae DS (2008) Osteoradionecrosis after three-dimensional conformal radiotherapy for recurrent cervical cancer presenting as a progressive osteolytic lesion. Ann Nucl Med 22(2):139-141, doi:10.1007/s12149-007-0090-3

Lee IJ, Koom WS, Lee CG, Kim YB, Yoo SW, Keum KC, Kim GE, Choi EC, Cha IH (2009) Risk factors and dose-effect relationship for mandibular osteoradionecrosis in oral and oropharyngeal cancer patients. Int J Radiat Oncol Biol Phys 75(4):1084-1091, doi:10.1016/j.jijrobp.2008.12.052

Lockhart PB, Clark J (1994) Pretherapy dental status of patients with malignant conditions of the head and neck. Oral Surg Oral Med Oral Pathol 77(3):236-241

Lozza L, Cerrotta A, Gardani G, De Marie M, Di Russo A, Kenda R, Tana S, Valvo F, Zucali R (1997) Analysis of risk factors for mandibular bone radionecrosis after exclusive low dose-rate brachytherapy for oral cancer. Radiother Oncol 44(2):143-147

Maier H, Zoller J, Herrmann A, Kreiss M, Heller WD (1993) Dental status and oral hygiene in patients with head and neck cancer. Otolaryngol Head Neck Surg 108(6):655-661

Mang C (2011) Retrospektive Untersuchung zur Häufigkeit und Risikofaktoren einer infizierten Radioosteonekrose bei Radiotherapie von Mundhöhlenkarzinomen. Thesis, Saarland University Homburg/Saar, Germany

Monnier Y, Broome M, Betz M, Bouferrache K, Ozsahin M, Jaques B (2011) Mandibular osteoradionecrosis in squamous cell carcinoma of the oral cavity and oropharynx: incidence and risk factors. Otolaryngol Head Neck Surg 144(5):726-732, doi:10.1177/0194599810396290

Nabil S (2012) Redefining osteoradionecrosis. Oral Surg Oral Med Oral Pathol Oral Radiol 114(3):403-404, doi:10.1016/j.0000.2012.04.031

Niewald M, Barbie O, Schnabel K, Engel M, Schedler M, Nieder C, Berberich W (1996) Risk factors and dose-effect relationship for osteoradionecrosis after hyperfractionated and conventionally fractionated radiotherapy for oral cancer. Br J Radiol 69(825):847-851

Niewald M, Fleckenstein J, Mang K, Holtmann H, Spitzer WJ, Rube C (2013) Dental status, dental rehabilitation procedures, demographic and oncological data as potential risk factors for infected osteoradionecrosis of the lower jaw after radiotherapy for oral neoplasms: a retrospective evaluation. Radiat Oncol 8(1):227

Oh HK, Chambers MS, Garden AS, Wong PF, Martin JW (2004) Risk of osteoradionecrosis after extraction of impacted third molars in irradiated head and neck cancer patients. J Oral Maxillofac Surg 62(2):139-144

Reuther T, Schuster T, Mende U, Kubler A (2003) Osteoradionecrosis of the jaws as a side effect of radiotherapy of head and neck tumour patients-a report of a thirty year retrospective review. Int J Oral Maxillofac Surg 32(3):289-295, doi:10.1054/ijom.2002.0332

Schuurhuis JM, Stokman MA, Roodenburg JL, Reintsema H, Langendijk JA, Vissink A, Spijkervet FK (2011) Efficacy of routine pre-radiation dental screening and dental follow-up in head and neck oncology patients on intermediate and late radiation effects. A retrospective evaluation. Radiother Oncol 101(3):403-409, doi:10.1016/j.radonc.2011.09.018

Schwartz HC, Kagan AR (2002) Osteoradionecrosis of the mandible: scientific basis for clinical staging. Am J Clin Oncol 25(2):168-171

Stenson KM, Kunnavakkam R, Cohen EE, Portugal LD, Blair E, Haraf DJ, Salama J, Vokes EE (2010) Chemoradiation for patients with advanced oral cavity cancer. Laryngoscope 120(1):93-99, doi:10.1002/lary.20716

Store G, Boysen M (2000) Mandibular osteoradionecrosis: clinical behaviour and diagnostic aspects. Clin Otolaryngol Allied Sci 25(5):378-384

Storey MR, Garden AS, Morrison WH, Eicher SA, Schechter NR, Ang KK (2001) Postoperative radiotherapy for malignant tumors of the submandibular gland. Int J Radiat Oncol Biol Phys 51(4):952-958

Studer G, Glanzmann C, Studer SP, Gratz KW, Bredell M, Locher M, Lutolf UM, Zwahlen RA (2011) Risk-adapted dental care prior to intensity-modulated radiotherapy (IMRT). Schweiz Monatsschr Zahnmed 121(3):216-229

Thiel HJ (1989) Osteoradionecrosis. I. Etiology, pathogenesis, clinical aspects and risk factors. Radiobiol Radiother (Berl) 30(5):397-413

Thorn JJ, Hansen HS, Specht L, Bastholt L (2000) Osteoradionecrosis of the jaws: clinical characteristics and relation to the field of irradiation. J Oral Maxillofac Surg 58(10):1088-1093, discussion 1093-1085. doi:10.1053/joms.2000.9562
Tsai CJ, Hofstede TM, Sturgis EM, Garden AS, Lindberg ME, Wei Q, Tucker SL, Dong $L$ (2012) Osteoradionecrosis and radiation dose to the mandible in patients with oropharyngeal cancer. Int J Radiat Oncol Biol Phys. doi:10.1016/ j.jirobp.2012.05.032

Turner SL, Slevin NJ, Gupta NK, Swindell R (1996) Radical external beam radiotherapy for 333 squamous carcinomas of the oral cavity-evaluation of late morbidity and a watch policy for the clinically negative neck. Radiother Oncol 41(1):21-29

doi:10.1186/2193-1801-3-263

Cite this article as: Niewald et al:: Dental status, dental treatment procedures and radiotherapy as risk factors for infected osteoradionecrosis (IORN) in patients with oral cancer - a comparison of two 10 years' observation periods. SpringerPlus 2014 3:263.

\section{Submit your manuscript to a SpringerOpen ${ }^{\odot}$ journal and benefit from:}

- Convenient online submission

- Rigorous peer review

- Immediate publication on acceptance

- Open access: articles freely available online

- High visibility within the field

- Retaining the copyright to your article

Submit your next manuscript at $>$ springeropen.com 